Supplement of Nat. Hazards Earth Syst. Sci., 19, 697-713, 2019

https://doi.org/10.5194/nhess-19-697-2019-supplement

(C) Author(s) 2019. This work is distributed under

the Creative Commons Attribution 4.0 License.

(c) (1)

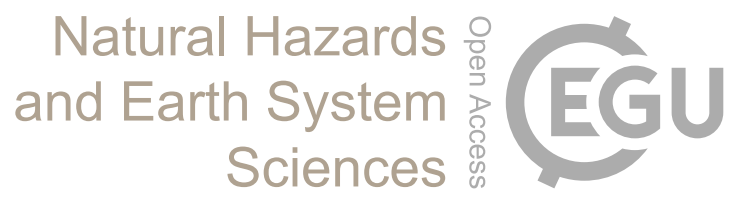

Supplement of

\title{
Event-based probabilistic risk assessment of livestock snow disasters in the Qinghai-Tibetan Plateau
}

Tao Ye et al.

Correspondence to: Yijia Li (liyijia@mail.bnu.edu.cn)

The copyright of individual parts of the supplement might differ from the CC BY 4.0 License. 


\section{Supplementary Figures and Tables}

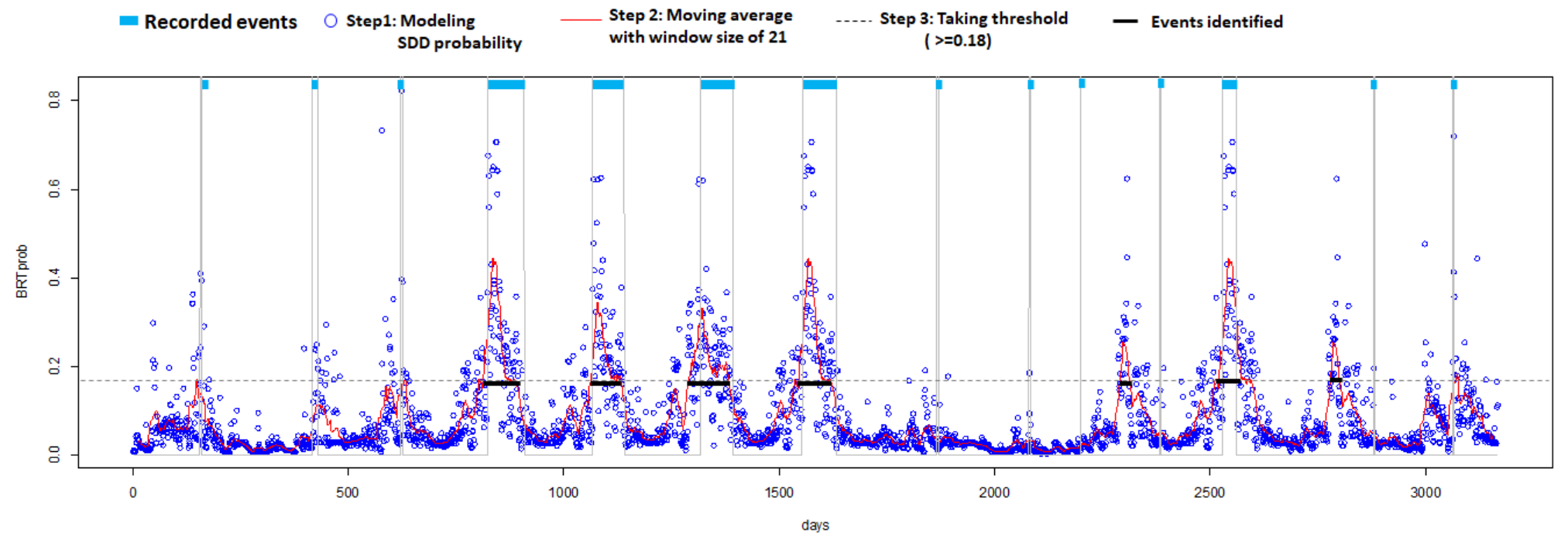

Fig. S1 Illustrative chart of the procedure for identifying snow disaster events, and its calibration with historical records. The time series is the conjunction 5 of days in the winter season (October 1 to May 31) with snow disaster records after 2008. In total, this includes 13 station •winter and 3168 single days. The figure shows that the procedure is capability of accurately capturing major historical events with relatively longer duration in terms of both timing of occurance and duration. 


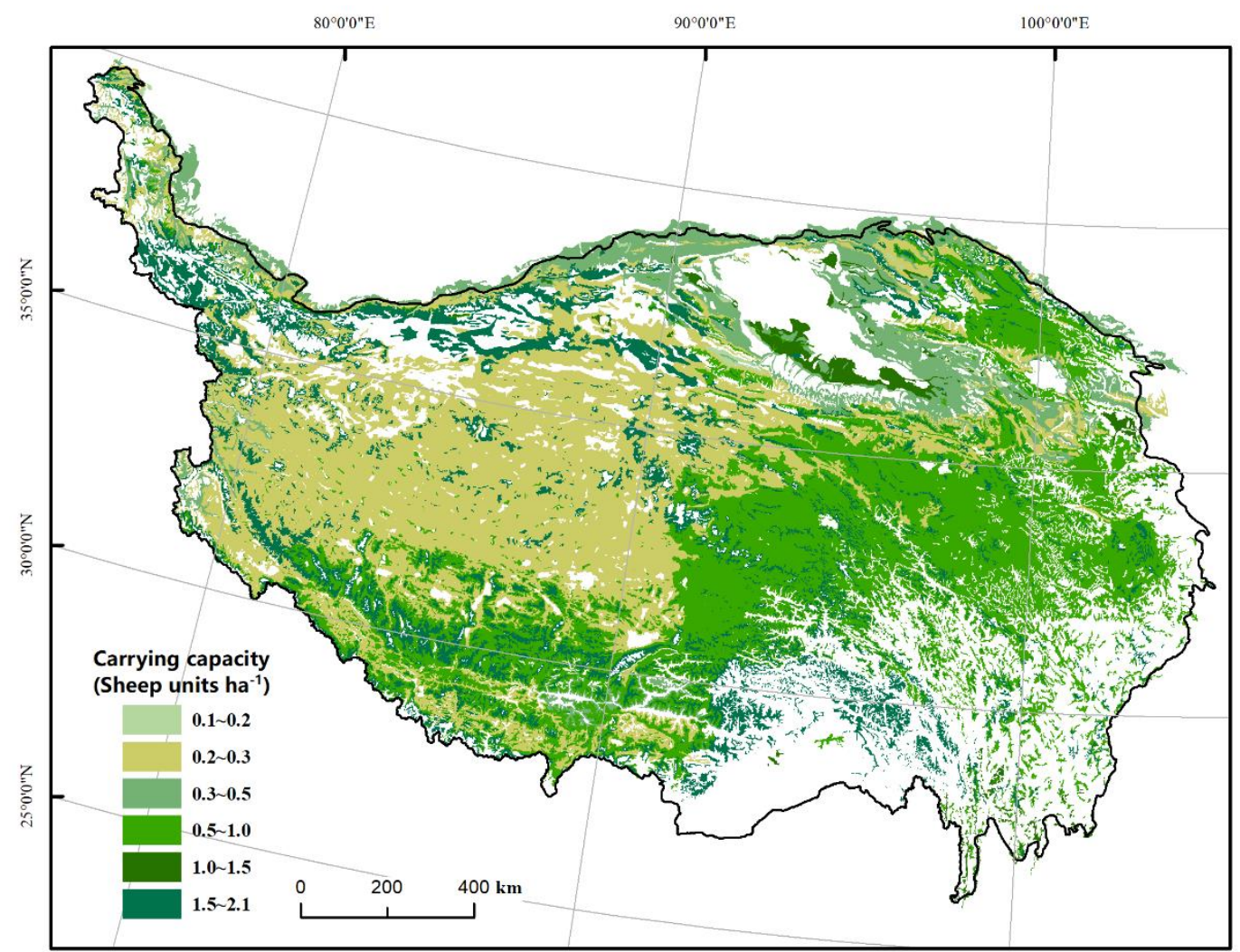

Fig. S2 Spatial distribution of livestock exposure estimated from vegetation distribution 

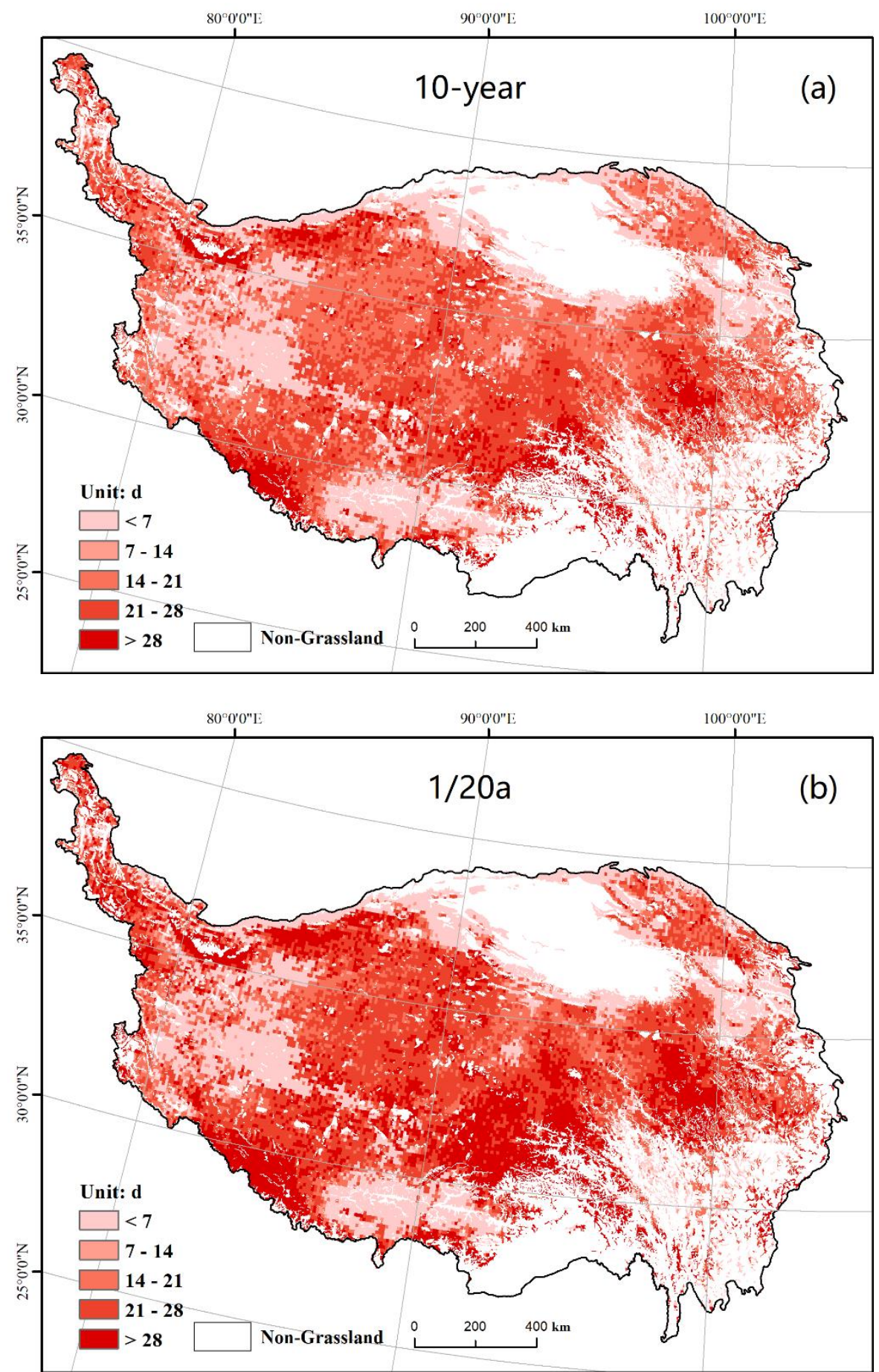

Fig. S3 Gridded duration of a single disaster event by return period: (a)10-year; (b) 20-year 
Table S1 Look-up table of carrying capacity by grassland type in the QTP

\begin{tabular}{|c|c|c|c|c|}
\hline Grassland type & $\begin{array}{l}\text { Fresh grass } \\
\text { yield }(\mathrm{kg} / \mathrm{ha})\end{array}$ & $\begin{array}{l}\text { Annual grazing } \\
\text { rate }(\%)\end{array}$ & $\begin{array}{l}\text { Grassland required } \\
\text { per sheep unit } \\
\text { (ha/unit) }\end{array}$ & $\begin{array}{l}\text { Carrying capacity } \\
\text { (sheep unit/ha) }\end{array}$ \\
\hline Alpine meadow & 1452 & 50 & 305.70 & 0.74 \\
\hline Alpine steppe & 677 & 40 & 819.30 & 0.27 \\
\hline Apline meadow-steppe & 689 & 45 & 745.20 & 0.30 \\
\hline Alpine desert-steppe & 554 & 35 & 1077.30 & 0.21 \\
\hline Apline desert & 519 & 30 & 988.95 & 0.23 \\
\hline Temperate steppe & 3018 & 40 & 170.10 & 1.32 \\
\hline Temperate desert & 683 & 30 & 1183.50 & 0.19 \\
\hline Temperate desert-steppe & 611 & 35 & 840.75 & 0.27 \\
\hline Lowland meadow & 3498 & 50 & 127.50 & 1.76 \\
\hline Mountain meadow & 3879 & 55 & 132.30 & 1.70 \\
\hline
\end{tabular}

Note: Figures were adapted from (Xin et al., 2011) and (Land Management Administration of Tibet Autonomous Region, 1994) 


\section{Supplementary material S1: Model details of the vulnerability function associated to Eq. (1)}

Vulnerability function Eq. (1) describes the quantitative relationship between the natural logarithm of livestock mortality rate $(\ln L R)$ and disaster duration (Duration), during disaster maximum daily mean wind speed (Wind), growing season (May-Sep) aggregate precipitation $(P)$, and prevention capacity as measured by fiscal expenditure of the local county government

5 (Fiscal_Exp) of the underlying county:

$\ln L R=\mathrm{s}($ Duration $)+s($ Wind $)+s(P)+s($ Fiscal_Exp $)$

The quantitative relationship was derived using generalized additive model, based on the data of 74 historical snow disaster event in the Qinghai-Tibet Plateau during 2008-2015 (Li et al. 2018).

Model fit statistics (Figure S1) indicate that all four variables are statistically significant. Adjusted- $\mathrm{R}^{2}$ is 0.563 and the overall

10 deviance explained is $62.5 \%$. Ten-fold cross-validation indicates that RMSE, MAE and ME for the model are 1.747, 1.325, and -0.002 , respectively.

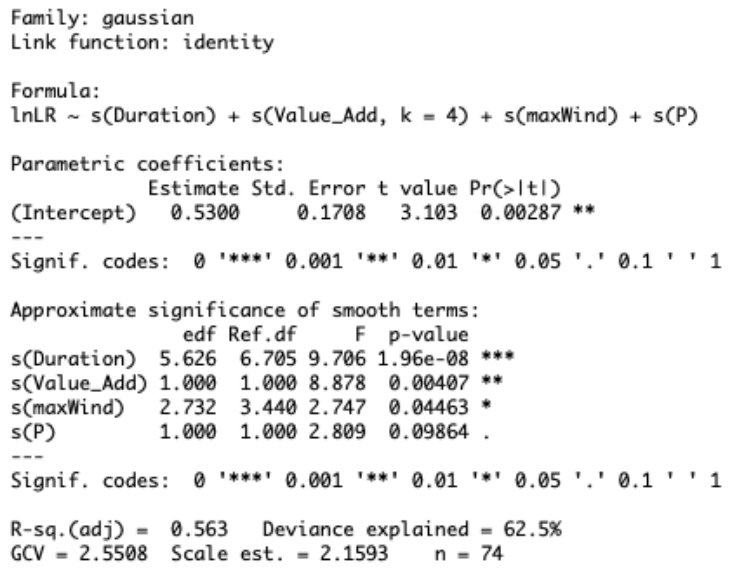

Figure S1: Model-fit statistics

Its response curves are provided in Figure S2. These curves indicate that: (1) $\ln L R$ is increasing with snow disaster duration.

15 Duration up to $15-18 \mathrm{~d}$ is a critical period that mortality will increase rapidly. (2) $\ln L R$ decreases with value added of animal husbandry (Value_Add), indicating the effect of stronger prevention capacity in reducing mortality, i.e. government expenditure in reserving hay for preparedness, and subsidy to herders to build/enlarge warm sheds. (3) An inverted-U shaped relationship between daily maximum wind speed and $\ln L R$. The up-slope part indicates the increasing stress of stronger wind on livestock, but the down-slope part (beyond 5-6 m/s) indicate herder's reaction to stop free-grazing and keep herds in shelters

20 (Wu et al. 2007). (4) $\ln L R$ decreases with growing season precipitation. Larger growing season precipitation indicates more abundant food for livestock in summer, and therefore better body-condition in resisting low temperature and lack of food in snow disaster times. 

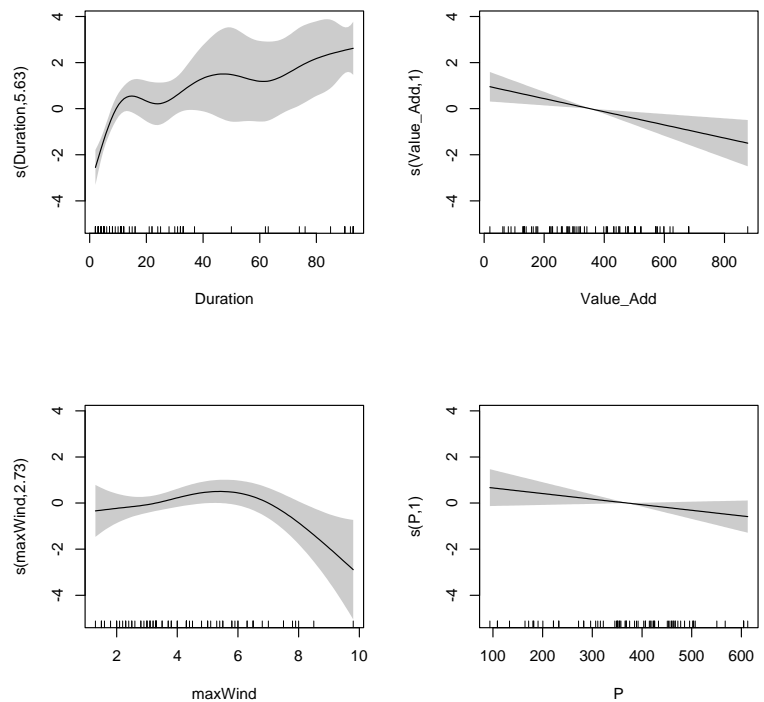

Figure S2: Response curves of the GAM model associated to Eq. (1)
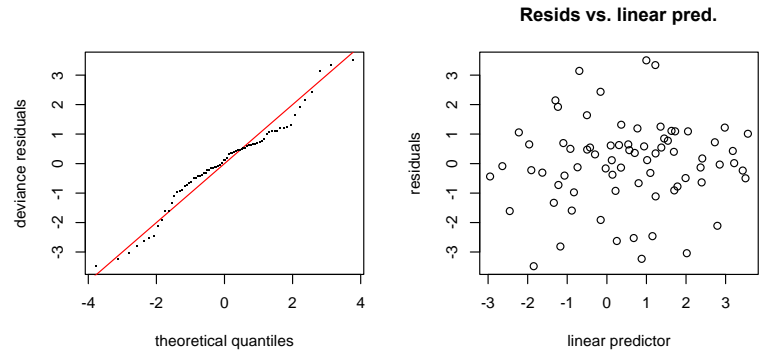

Histogram of residuals

Response vs. Fitted Values
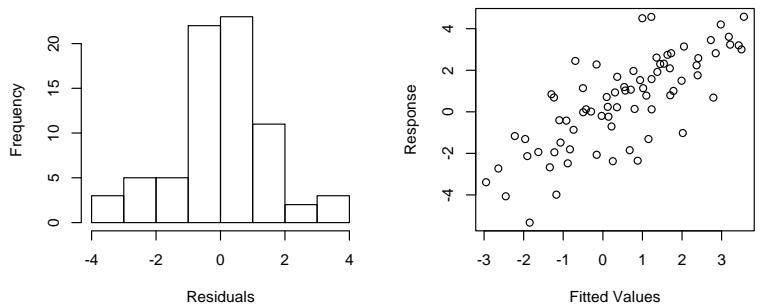

Figure S3: Perfomance diagnostics charts for the GAM model associated to Eq. (1)

5 The performance diagnostics charts of the model (Figure S3) indicate that 1) QQ plot is very close to a straight line, suggesting our distributional assumption of normality is reasonable. 2) the variance is approximately constant as the mean increases. 3) The histogram of residuals appears approximately consistent with normality. 4) the response against fitted values show a positive linear relationship in the scatter plot. 
For more details of data, variable used, model fitting and variable selection, please refer to Li et al. (2018) and Ye et al. (2018; under review). 